OPEN ACCESS

Edited by:

Ranjith Ramasamy,

University of Miami, United States

Reviewed by:

Thomas A. Masterson, University of Miami Health System,

United States

Nannan Thirumavalavan, Baylor College of Medicine, United States

*Correspondence:

Rossella Mazzill rossella.mazzilli@uniroma1.it; rossella.mazzill@gmail.com

Specialty section: This article was submitted to Reproduction, a section of the journa Frontiers in Endocrinology

Received: 20 February 2019 Accepted: 09 May 2019

Published: 04 June 2019

Citation:

Mazzilli R, Stigliano A, Delfino M, Olana S, Zamponi V, Iorio $C$, Defeudis G, Cimadomo D, Toscano V and Mazzilli $F$ (2019) The High Prevalence of Testicular Adrenal Rest Tumors in Adult Men With Congenital Adrenal Hyperplasia Is Correlated With ACTH Levels.

Front. Endocrinol. 10:335 doi: 10.3389/fendo.2019.00335

\section{The High Prevalence of Testicular Adrenal Rest Tumors in Adult Men With Congenital Adrenal Hyperplasia Is Correlated With ACTH Levels}

\author{
Rossella Mazzilli ${ }^{1,2 *}$, Antonio Stigliano ${ }^{2}$, Michele Delfino ${ }^{1}$, Soraya Olana ${ }^{1}$, \\ Virginia Zamponi ${ }^{1,2}$, Cristina lorio ${ }^{1,2}$, Giuseppe Defeudis ${ }^{3}$, Danilo Cimadomo ${ }^{4}$, \\ Vincenzo Toscano ${ }^{2}$ and Fernando Mazzilli ${ }^{1,2}$
}

${ }^{1}$ Andrology Unit, Department of Clinical and Molecular Medicine, Sant'Andrea Hospital, University of Rome "Sapienza", Rome, Italy, ${ }^{2}$ Endocrinology Unit, Department of Clinical and Molecular Medicine, Sant'Andrea Hospital, University of Rome "Sapienza", Rome, Italy, ${ }^{3}$ Unit of Endocrinology and Diabetes, Department of Medicine, Campus Bio-Medico University of Rome, Rome, Italy, ${ }^{4}$ G.E.N.E.R.A Centers for Reproductive Medicine, Rome, Italy

Introduction: The aims of this study were to determine the prevalence of testicular-adrenal rest tumors (T-ARTs) in patients with congenital adrenal hyperplasia $(\mathrm{CAH})$ and to evaluate the related ultrasound (US) features, hormonal profiles, and semen parameters. Therefore, we attempted to understand the potential impact of adrenocorticotropic hormone (ACTH) on the persistence or disappearance of T-ART.

Methods: We conducted a longitudinal cohort study including patients with $\mathrm{CAH}$ who were undergoing treatment with cortisone and, when indicated, fludrocortisone replacement therapy. We performed andrological examinations, US of the testis, hormone profiling, and semen analysis.

Results: Of the 25 patients (mean \pm SD age, $32.2 \pm 7.5$ years), T-ARTs were detected by US in 14 (56.0\%) patients. The mean \pm SD diameter of the lesions was $13.2 \pm 6.8 \mathrm{~mm}$. Among $3(21.4 \%)$ patients, the lesions were observed in one testis, whereas both testes were affected in the remaining 11 (78.6\%) patients. The lesions were hypoechoic in 12 (85.7\%) patients and hyperechoic in 2 (14.3\%). Plasma ACTH and 17-hydroxyprogesterone (17-OHP) levels were significantly higher in patients with T-ART than in patients without lesions $(319.4 \pm 307.0 \mathrm{pg} / \mathrm{ml}$ and $12.4 \pm 2.7 \mathrm{ng} / \mathrm{ml} \mathrm{vs}$. $33.5 \pm 10.7 \mathrm{pg} / \mathrm{ml}$ and $8.2 \pm 1.8 \mathrm{ng} / \mathrm{ml}$, respectively; $p<0.01)$. The mean values of sperm concentration and motility were significantly lower in patients with T-ART than in patients without lesions $\left(12.1 \pm 12.4 \times 10^{6} \mathrm{cells} / \mathrm{ml}\right.$ and $18.4 \pm 11.1 \%$ vs. 41.5 $\pm 23.2 \times 10^{6} \mathrm{cells} / \mathrm{ml}$ and $30.8 \pm 15.4 \%$, respectively; $\left.p<0.05\right)$. Logistic regression analysis showed ACTH level as a significant predictor of T-ART $(p<0.05)$. In patients with T-ART, the dose of hydrocortisone was increased by 25-30\%, while the fludrocortisone treatment remained unchanged. After 6 months of steroid treatment, patients underwent US and hormonal evaluation. Disappearance and a reduction in T-ART were observed in 6 (42.9\%) and 5 (35.7\%) patients, respectively; a reduction in ACTH levels (from 319.4 \pm 307.0 to $48.1 \pm 5.1 \mathrm{pg} / \mathrm{ml} ; p<0.01$ ) was reported. A significant correlation between ACTH level reduction and T-ART diameter reduction was observed $(p<0.5 ; r=0.55)$. 
Conclusions: T-ARTs were detected in $56 \%$ of patients with CAH and were associated with impaired semen parameters. However, these lesions are potentially reversible, as demonstrated by the disappearance/reduction after adjustment of cortisone therapy and by the reduction in plasma ACTH level. Our study supports the importance of periodic US evaluation and maintenance of plasma ACTH levels within the normal range in men with $\mathrm{CAH}$.

Keywords: congenital adrenal hyperplasia, testicular lesion, semen analysis, male infertility, testicular adrenal rest tumor, azoospermia, testosterone, cortisol

\section{INTRODUCTION}

Congenital adrenal hyperplasia $(\mathrm{CAH})$ is a group of rare inherited autosomal recessive disorders that occurs at an incidence of $1 / 10,000-20,000(1,2)$. In $\geq 90 \%$ of cases, $\mathrm{CAH}$ is caused by a mutation in the CYP21A2 gene that leads to a deficiency of 21-hydroxylase (CYP21), due to CYP21A2 gene mutations.

This enzyme converts 17-hydroxyprogesterone (17OHP) into 11-deoxycortisol and progesterone into 11deoxycorticosterone-the precursors of cortisol and aldosterone, respectively. Consequently, the levels of cortisol and, in some cases, aldosterone reduce.

Testicular adrenal rest tumors (T-ARTs) represent islands of adrenal tissue that remain within the gonads during embryonic development. The presence of these lesions has been described in patients with $\mathrm{CAH}$, with a prevalence ranging from 0 to 94\% (3-10).

Adrenal rest tissue may migrate with the gonads during their descent (4). Furthermore, the deficit in cortisol production in $\mathrm{CAH}$ causes a reduction in negative pituitary feedback, resulting in an increase in adrenocorticotrophic hormone (ACTH) levels. This causes adrenal gland hypertrophy and the overstimulation of ectopic adrenal cells located in the testes. T-ARTs can cause seminal alterations owing to the effects of compression exerted on the rete testis. Moreover, high levels of ACTH indirectly interfere with spermatogenesis in these patients. In fact, increased levels of ACTH induce an adrenal-derived androgens excess that can cause negative feedback on the pituitary and hypothalamus, with a consequent suppression of gonadotropins and testicular testosterone production. Therefore, this mechanism can impair spermatogenesis (3).

In particular, in cases of the heterozygous form of the disease, T-ARTs may remain unrecognized for several years. Previous studies have confirmed the high prevalence of T-ARTs in patients with $\mathrm{CAH}$, and it was hypothesized that ACTH plasma levels play a role in the pathogenesis (8).

In $\mathrm{CAH}$ patients, the diagnosis of oligozoospermia or azoospermia, or the detection of one or more small size masses in the testis may lead to the suspicion of T-ART. Furthermore, the presence of a testicular mass could be interpreted as a malignancy.

The aims of this study were to determine the prevalence of $\mathrm{T}$ ART in patients with CAH and to evaluate the ultrasound (US) features, hormonal profiles, and semen parameters. Therefore, we attempted to understand the potential impact of ACTH on the persistence or disappearance of T-ART.

\section{MATERIALS AND METHODS}

Male patients with CAH, who were referred to our endocrinological unit between January 2006 and September 2017, were included in this longitudinal cohort study and underwent an andrological evaluation to evaluate possible complication of CAH. Inclusion criteria were male sex and $\mathrm{CAH}$ due to 21-hydroxylase deficiency. Exclusion criteria were the presence of $\mathrm{CAH}$ due to other enzymatic defects in cortisol synthesis.

The patients had been receiving glucocorticoids (hydrocortisone $15-25 \mathrm{mg} / \mathrm{m}^{2}$, thrice daily) and, when indicated, fludrocortisone (0.05-0.2 mg, 1-2 times/daily) replacement therapy for $\geq 1$ year.

Written informed consent was obtained from all individual participants who were included in the study. The study was conducted according to "Sapienza" University of Rome Ethics Committee.

The study included andrological clinical examinations, US of the testis, hormonal profiling, and standard semen analysis. The andrological examination was aimed at evaluating the testis (shape, size, and appearance), epididymis, penis, and body hair distribution, and the possible presence of gynecomastia. US and color Doppler sonography were performed with a linear transducer probe of $7 \mathrm{MHz}$ (Philips Ultrasound Machine HDI 4000). To study the morphology, testicular size was evaluated using an ellipsoid formula (length $\times$ width $\times$ depth $\times 0.52$ ) (11). Blood samples were obtained at 8:00 am; the plasma levels of luteinizing hormone ( $\mathrm{LH})$, follicle stimulating hormone (FSH), testosterone, ACTH, 17-OHP, and cortisol were measured. Chemiluminescence microparticle immunoassay (CMIA) was used to detect testosterone; chemiluminescence immunoassay (CLIA) for 17-OHP, FSH, and LH; and LIAISON CLIA for ACTH and cortisol. Serum potassium and sodium levels were analyzed by ion-selective electrode method, fasting blood glucose was analyzed by enzymatic methods, and insulin was analyzed by microparticle enzyme immunoassay. Semen analysis was carried out according to 1999-2010 WHO guidelines $(12,13)$. Samples of sperm were collected by masturbation after sexual abstinence from 2 to 7 days. Sperm concentration and motility were evaluated using the 
TABLE 1 | Hormonal profile in patients without testicular adrenal rest tumor and with testicular adrenal rest tumor at basal condition and after 6 months of modified glucocorticoid treatment.

\begin{tabular}{|c|c|c|c|c|}
\hline & $\begin{array}{c}\text { No T-ART } \\
(n=11) \\
\text { Mean } \pm \text { SD (min-max) }\end{array}$ & $\begin{array}{c}\text { T-ART basal } \\
(n=14) \\
\text { Mean } \pm \text { SD (min-max) }\end{array}$ & $\begin{array}{c}\text { T-ART } 6 \text { months } \\
(n=14) \\
\text { Mean } \pm \text { SD (min-max) }\end{array}$ & $P$-value \\
\hline ACTH (pg/ml) & $33.5 \pm 10.7(11-45)$ & $319.4 \pm 307.0$ (55-950) & $48.1 \pm 5.1(39-55)$ & $<0.01$ \\
\hline 17-OHP (ng/ml) & $8.2 \pm 1.8(5.1-10.2)$ & $12.4 \pm 2.7(8.9-18.4)$ & $8.0 \pm 1.2(6.3-10.3)$ & $<0.01$ \\
\hline FSH (mlU/ml) & $3.6 \pm 1.7(1.2-6.4)$ & $2.8 \pm 1.4(1.1-6.0)$ & $3.0 \pm 1.4(1.6-6.1)$ & N.S. \\
\hline $\mathrm{LH}(\mathrm{mlU} / \mathrm{ml})$ & $2.9 \pm 1.1(1.8-5.1)$ & $2.6 \pm 1.3(1.2-4.9)$ & $2.6 \pm 1.2(1.3-5.1)$ & N.S. \\
\hline Testosterone (ng/ml) & $4.5 \pm 0.9(3.1-6.1)$ & $5.3 \pm 1.3(3.1-8.0)$ & $5.2 \pm 1.3(3.4-8.1)$ & N.S. \\
\hline
\end{tabular}

T-ART, testicular adrenal rest tumor; T-ART basal, basal condition; T-ART 6 months, hormonal profile after 6 months.

TABLE 2 | Semen parameters in patients without and with testicular adrenal rest tumor.

\begin{tabular}{|c|c|c|c|}
\hline & $\begin{array}{c}\text { No T-ART } \\
(n=11) \\
\text { Mean } \pm \text { SD (min-max) }\end{array}$ & $\begin{array}{c}\text { T-ART } \\
(n=14) \\
\text { Mean } \pm \text { SD (min-max) }\end{array}$ & $P$-value \\
\hline Volume (ml) (>1.5 ml) & $2.7 \pm 0.7(1.6-4.1)$ & $1.9 \pm 0.5(1.1-3.0)$ & $<0.05$ \\
\hline $\mathrm{N} / \mathrm{ml}\left(>15 \times 10^{6}\right)$ & $41.5 \pm 23.2(4.0-84.0)$ & $12.1 \pm 12.4(0-36.0)$ & $<0.01$ \\
\hline Progressive motility (\%) (>32\%) & $30.8 \pm 15.4(3.0-50.0)$ & $18.4 \pm 11.1(0-38.0)$ & $<0.05$ \\
\hline Atypical form (\%) (<96\%) & $69.8 \pm 8.5(61.0-89.0)$ & $76.7 \pm 8.3$ (59.0-96.0) & N.S. \\
\hline
\end{tabular}

T-ART, testicular adrenal rest tumor.

Superimposed Image Analysis System (SIAS) as described previously (14).

\section{Statistical Analysis}

Continuous data were described as absolute values, mean \pm standard deviation (SD), and range. Categorical data were described as absolute number, percentage frequency, and $95 \%$ confidence intervals (CI). We used Fisher's exact test for analyzing categorical data; $p<0.05$ was considered statistically significant. The software $\mathrm{R}$ version 2.14.2 (Free Software Foundation, Inc., USA) was used for statistics and logistic regression analyses.

\section{RESULTS}

All patients were post-pubertal and the mean \pm SD of the age was $32.2 \pm 7.5$ years (range, $18-43$ years). The mean \pm SD of hydrocortisone dosage was $18.5 \pm 2.6 \mathrm{mg} /$ day (range, 15-22.5 $\mathrm{mg} /$ day), and all patients were in normal weight range (BMI mean \pm SD: $22.5 \pm 1.1 \mathrm{~kg} / \mathrm{m}^{2}$; range, $20.8-24.1 \mathrm{~kg} / \mathrm{m}^{2}$ ). Only 2/25 men had previously conceived.

The physical examination of the scrotum showed a palpable testicular mass only in one patient (4.0\%). The remaining patients did not have any masses. None of the patients showed objective anomalies of testis, epididymis, penis, and body hair distribution or gynecomastia.

The testicular size, evaluated using US, was within the normal range in all patients (mean \pm SD in right testis: $17.7 \pm 1.9 \mathrm{ml}$; range, $15-21.3 \mathrm{ml}$; mean $\pm \mathrm{SD}$ in left testis: $17.2 \pm 1.7 \mathrm{ml}$; range, $14.9-20.7 \mathrm{ml})$.
T-ARTs were detected by US in 14/25 (56.0\%) patients. The mean diameter of the lesions was $13.2 \pm 6.8 \mathrm{~mm}$ (range, 4$26 \mathrm{~mm}$ ). In $3 / 14$ patients $(21.4 \%)$, the lesion involved only one testis, while in $11 / 14$ patients $(78.6 \%)$, both the testes were affected.

In $12 / 14$ patients ( $85.7 \%$ ), the lesions were largely hypoechoic. In the remaining $2 / 14$ patients (14.3\%), the lesions were largely hyperechoic. Color Doppler US showed an absence of flow in $10 / 14$ (71.4\%) patients, perilesional flow in 3/14 (21.4\%) patients, and perilesional and intralesional flow in the remaining patient $(1 / 14 ; 7.1 \%)$.

No differences in testicular size and in potassium, sodium, insulin, and fasting blood glucose concentration were observed in patients with and without T-ART. Plasma levels (mean \pm SD values) of ACTH, 17-OHP, FSH, LH, and testosterone are shown in Table 1. The mean value of ACTH was above the normal range in all patients with T-ART. Both ACTH and 17-OHP levels were significantly higher in patients with T-ART $(319.4 \pm 307.0 \mathrm{pg} / \mathrm{ml}$ and $12.4 \pm 2.7 \mathrm{ng} / \mathrm{ml}$, respectively) than in patients without lesions $(33.5 \pm 10.7 \mathrm{pg} / \mathrm{ml}$ and $8.2 \pm 1.8 \mathrm{ng} / \mathrm{ml}$, respectively; $p<0.01)$.

Semen analysis showed azoospermia in $2(14.3 \%)$ patients and normospermia in $3(21.4 \%)$ patients with T-ART. The mean values of semen volume, sperm concentration, and progressive motility were significantly lower in patients with T-ART $(2.7 \pm$ $0.7 \mathrm{ml}, 12.1 \pm 12.4 \times 10^{6}$ cells $/ \mathrm{ml}$, and $18.4 \pm 11.1 \%$, respectively) than in patients without lesions $(1.9 \pm 0.5 \mathrm{ml}, 41.5 \pm 23.2 \times$ $10^{6}$ cells $/ \mathrm{ml}$, and $30.8 \pm 15.4 \%$, respectively; $p<0.05$ ) (Table 2 ). None of the patients with T-ART had previously conceived.

Logistic regression analyses were conducted to investigate all the possible basal confounders upon the presence of T-ART 
TABLE 3 | Semen parameters in patients with testicular adrenal rest tumor who repeated semen analysis after 6 months of modified glucocorticoid treatment.

\begin{tabular}{|c|c|c|c|}
\hline & $\begin{array}{c}\text { T-ART basal } \\
(n=10) \\
\text { Mean } \pm \text { SD (min-max) }\end{array}$ & $\begin{array}{c}\text { T-ART } 6 \text { months } \\
(n=10) \\
\text { Mean } \pm \text { SD (min-max) }\end{array}$ & $P$-value \\
\hline Volume (ml) (>1.5 ml) & $1.8 \pm 0.4(1.1-2.2)$ & $1.9 \pm 0.3(1.4-2.3)$ & N.S. \\
\hline $\mathrm{N} / \mathrm{ml}\left(>15 \times 10^{6}\right)$ & $8.7 \pm 8.8(0-29)$ & $15.4 \pm 12.7(0-41)$ & N.S. \\
\hline Progressive motility (\%) (>32\%) & $16.9 \pm 6.7(10.0-30.0)$ & $16.8 \pm 8.0(0-28.0)$ & N.S. \\
\hline Atypical form (\%) (<96\%) & $73.8 \pm 6.0(63.0-83.0)$ & $75.6 \pm 0.4(61.0-96.0)$ & N.S. \\
\hline
\end{tabular}

T-ART, testicular adrenal rest tumor; T-ART basal, basal condition; T-ART 6 months, semen parameters after 6 months.

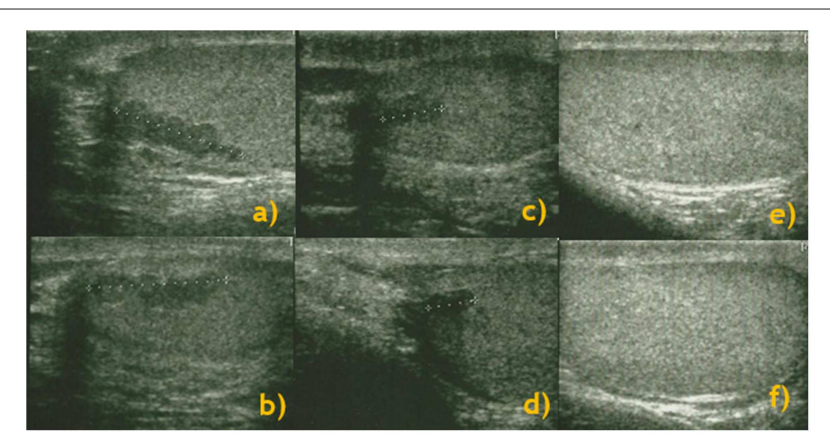

FIGURE 1 | Longitudinal study: testis ultrasound performed at baseline [right (a) and left (b) testes], and 3 months [right (c) and left (d) testes] and 6 months [right (e) and left (f) testes] after cortisone therapy and a consequent improvement in ACTH levels.

(i.e., age, testis size, BMI, hydrocortisone dosage, basal ACTH, $\mathrm{LH}, \mathrm{FSH}$, testosterone, and 17-OHP) and to evaluate possible correlation between T-ART size and hormonal level and between T-ART size and semen parameters. Only the ACTH level $(p<0.05)$ was shown as a significant predictor of T-ART.

In patients with $\mathrm{T}$-ART, the dose of hydrocortisone was increased by $\sim 25-30 \%$ with respect to the body mass surface of the patients (from $18.0 \pm 2.2 \mathrm{mg}$ /day; range, $15-22.5$ to $22.5 \pm$ $2.2 \mathrm{mg} /$ day; range, $17.5-25 \mathrm{mg} /$ day), while the fludrocortisone treatment remained unchanged. After 6 months of steroid treatment, all patients underwent US and hormonal evaluation, and 10/14 patients also underwent semen analysis (Tables 1, 3).

US showed a disappearance or reduction in $11(78.6 \%) \mathrm{T}$ ART patients. In particular, in $5(45.5 \%)$ patients, we observed a reduction in the lesion diameter, while in the remaining 6 (54.5\%) patients, there was a total disappearance of lesions. Figure 1 represents the evolution of lesions after 3 and 6 months of modified glucocorticoid treatment.

A significant reduction in plasma ACTH and 17-OHP levels was observed (from $319.4 \pm 307.0$ to $48.1 \pm 5.1 \mathrm{pg} / \mathrm{ml}$ and from $12.4 \pm 2.7$ to $8.0 \pm 1.2 \mathrm{ng} / \mathrm{ml}$, respectively; $p<0.01$ ), while the other hormonal levels remained similar to the basal condition (Table 1). A linear regression analysis and a Pearson correlation test highlighted a correlation between ACTH level reduction and T-ART diameter reduction $(p<0.5 ; r=0.55)$.

The follow-up of semen parameters was obtained in 10/14 patients with T-ART. An improvement in sperm number (from
$8.7 \pm 8.8 \times 10^{6}$ to $15.4 \pm 12.7 \times 10^{6}$ cells $/ \mathrm{ml}$ ) was observed in such patients, but the comparison was not statistically significant (Table 3). Probably, this is due to the small number of patients. The other semen parameters remained unchanged.

Finally, none of these patients showed pathologically high blood glucose values or insulin resistance.

\section{DISCUSSION}

$\mathrm{CAH}$ represents a group of autosomal recessive disorders characterized by enzymatic defects in the cortisol biosynthesis pathway. Treatment of CAH includes the use of glucocorticoids and, when indicated, mineralocorticoid replacement therapy. Clinical manifestations in the neonatal stage include adrenal insufficiency symptoms (e.g., vomiting, dehydration), ambiguous genitalia, and skin hyperpigmentation (2). A complication in adult patients with $\mathrm{CAH}$ is the presence of intratesticular area of ectopic adrenal tissue in the testis. The prevalence of this condition among men affected by CYP21 deficiency varies between 0 and $94 \%(3-10)$. The variability could be attributed to heterogeneity in the selection of patients, age, and the various glucocorticoid treatment regimens. In fact, Kim et al. (15) suggested that the prevalence of T-ART is high in young men with $\mathrm{CAH}$, but low in infants or elderly patients.

Here, we studied the prevalence of T-ART, the hormonal profile, the US features, and the semen parameters in patients with CAH. According to previous studies $(8,16)$, the prevalence of T-ART could be higher than 50\%. US features showed a higher prevalence of bilateral and hypoechoic area and the absence of intra-lesional flow in the T-ART. Differential diagnosis of other testicular lesions, such as Leydig cell tumors, could be performed following certain criteria that suggest T-ARTs are bilateral in a high percentage of cases; patients with Leydig cell tumors had gynecomastia. The definitive histological differential diagnosis is based on the absence of Insulin-like 3 and Reinke crystalloids in T-ART (17).

Ahmad et al. suggested the use of MRI in a patient with $\mathrm{CAH}$ (18). Adrenal cortex is isointense with muscle on T1- and T2-weighted images. T-ARTs have the same characteristics as the testicular parenchyma. Injection of gadolinium revealed a homogeneous enhancement. To date, MRI is not considered a gold standard in the study of the testes. In the present study, more than $80 \%$ of the patients had bilateral lesions, and none of the patients showed gynecomastia. 
Importantly, the study showed a reduction or a disappearance of the lesions in more than $75 \%$ of the cases after a modification of the cortisone therapy and a significant reduction in plasma ACTH level. The result was further corroborated by (a) the detection of high ACTH levels in all patients with T-ART and normal levels in patients without testicular lesions, (b) logistic regression analysis showing ACTH level as a significant predictor of T-ART, and (c) the significant correlation between reduction of ACTH levels and reduction of T-ART diameters. The role of ACTH in the induction of T-ART has been previously shown also in patients with Cushing syndrome who developed a testicular mass $\geq 10$ years after bilateral adrenalectomy (19).

For this reason, T-ART should be suspected not only in $\mathrm{CAH}$ patients, but in all men with potentially high ACTH levels (i.e., Cushing syndrome, Addison disease, and adrenalectomy).

Treatment with excessively high dose of glucocorticoids must be avoided as it may lead to the development of diabetes and obesity, insulin resistance, and osteoporosis $(1,2,20,21)$. Glucocorticoid-induced hyperglycemia depends on the total glucocorticoid dose and duration of therapy and may occur also in $<1$ month (22). Therefore, metabolic parameters should be examined. In the present study, none of these patients developed diabetes or insulin resistance during follow-up.

Our results also underlined, in accordance with previous studies $(10,23-27)$, the increased risk of infertility in men with CAH. In the presence of T-ART, semen analysis showed a condition of oligoasthenoteratozoospermia or azoospermia in about $85 \%$ of the cases. The alterations may be caused by ACTH interference because of a feedback loop and a consequent suppression of gonadotropins and testicular testosterone production, or a compression on the rete testis in the presence of a testicular mass, as described previously $(3,24)$. In the present study, the mechanism seems to be mostly due to

\section{REFERENCES}

1. Mass Screening Committee, Japanese Society for Pediatric Endocrinology, and Japanese Society for Mass Screening, Ishii T, Anzo M, Adachi M, Onigata K, Kusuda S, et al. Guidelines for diagnosis and treatment of 21hydroxylase deficiency (2014 revision). Clin Pediatr Endocrinol. (2015) 24:77105. doi: $10.1297 /$ cpe. 24.77

2. Speiser PW, Azziz R, Baskin LS, Ghizzoni L, Hensle TW, Merke DP, et al. Endocrine Society: congenital adrenal hyperplasia due to steroid 21-hydroxylase deficiency: an Endocrine Society clinical practice guideline. J Clin Endocrinol Metab. (2010) 95:4133-60. doi: 10.1210/jc.200 9-2631

3. Auchus JR. Management considerations for the adult with congenital adrenal hyperplasia. Mol. Cell Endocrinol. (2015) 408:190-7. doi: 10.1016/j.mce.2015.01.039

4. Barwick TD, Malhotra A, Webb JA, Savage MO, Reznek RH. Embryology of the adrenal glands and its relevance to diagnostic imaging. Clin. Radiol. (2005) 60:953-9. doi: 10.1016/j.crad.2005.04.006

5. Stikkelbroeck NM, Otten BJ, Pasic A, Jager GJ, Sweep CG, Noordam $\mathrm{K}$, et al. High prevalence of testicular adrenal rest tumors, impaired spermatogenesis, and Leydig cell failure in adolescent and adult males with congenital adrenal hyperplasia. J. Clin. Endocrinol. Metab. (2001) 86:5721-8. doi: $10.1210 /$ jcem. 86.12 .8090 a compression, since the gonadotropins were within the normal range, both in basal condition and after 6 months.

The main limitation of this study is the low sample number; this is due to the low incidence of $\mathrm{CAH}$, and it could be difficult to recruit patients for a study when the disease has low incidence. Moreover, not all patients accepted to perform the follow-up for semen analysis; therefore, we cannot conclude that the reduction/disappearance of T-ART was correlated with a significant improvement of sperm parameters. Further studies with more T-ART patients are needed to clarify this aspect.

In conclusion, this study confirms the high prevalence of $\mathrm{T}$ ART in patients with CAH and an association with impaired semen parameters. However, these lesions are potentially reversible, as demonstrated by the disappearance/reduction postadjustment of cortisone therapy and by the reduction in plasma ACTH level. Therefore, ACTH level should be maintained, as much as possible, within the normal range, as opposed to the usual suggestion in the treatment of CAH patients without TART. Finally, the study supports the importance of periodic US evaluation and maintenance of plasma ACTH levels within the normal range in men with $\mathrm{CAH}$, as suggested in the guidelines $(2,28)$. The differential diagnosis between T-ART and other testicular sonographic anomalies is crucial to avoid unnecessary surgery.

\section{DATA AVAILABILITY}

The datasets generated for this study are available on request to the corresponding author.

\section{AUTHOR CONTRIBUTIONS}

FM, VT, and RM conceived the study. RM and AS drafted the manuscript. All authors contributed to data collection and/or interpretation and provided a critical revision of the manuscript.

6. Falhammar H, Nyström HF, Ekström U, Granberg S, Wedell A, Thorén M. Fertility, sexuality and testicular adrenal rest tumors in adult males with congenital adrenal hyperplasia. Eur. J. Endocrinol. (2012) 166:441-9. doi: 10.1530/EJE-11-0828

7. Pierre P, Despert F, Tranquart F, Coutant R, Tardy V, Kerlan V, et al. Adrenal rest tissue in gonads of patients with classical congenital adrenal hyperplasia: multicenter study of 45 French male patients. Ann Endocrinol. (2012) 73:51522. doi: 10.1016/j.ando.2012.09.005

8. Delfino M, Elia J, Imbrogno N, Argese N, Mazzilli R, Toscano V, et al. Testicular adrenal rest tumors in patients with congenital adrenal hyperplasia: prevalence and sonographic, hormonal, and seminal characteristics. $J$ Ultrasound Med. (2012) 31:383-8. doi: 10.7863/jum.2012.31.3.383

9. Reisch N, Rottenkolber M, Greifenstein A, Krone N, Schmidt H, Reincke $\mathrm{M}$, et al. Testicular adrenal rest tumors develop independently of long-term disease control: a longitudinal analysis of 50 adult men with congenital adrenal hyperplasia due to classic 21-hydroxylase deficiency. J Clin Endocrinol Metab. (2013) 98:1820-6. doi: 10.1210/jc.2012-3181

10. Chihaoui M, Kanoun F, Chaker F, Yazidi M, Bouchrit K, Mizouni H, et al. Testicular adrenal rest tumours in young adult males with congenital adrenal hyperplasia: prevalence and impact on testicular function. Andrologia. (2016) 48:45-50. doi: 10.1111/and.12416

11. Lenz S, Giwercman A, Elsborg A, Cohr KH, Jelnes JE, Carlsen E, et al. Ultrasonic testicular texture and size in 444 men from the general 
population: Correlation to semen quality. Eur. Urol. (1993) 24:231-8. doi: 10.1159/000474300

12. World Health Organization. Laboratory Manual for the Examination of Human Semen and Sperm Cervical Mucus Interaction. 4th ed. New York, NY: Cambridge University Press (1999).

13. World Health Organization. Laboratory Manual for the Examination and Processing of Human Semen. 5th ed. New York, NY: Cambridge University Press (2010).

14. Mazzilli F, Rossi T, Delfino M, Nofroni I. Application of the upgraded image superimposition system (SIAS) to the assessment of sperm kinematics. Andrologia. (1999) 31:187-94. doi: 10.1046/j.1439-0272.1999.00276.x

15. Kim MS, Goodarzian F, Keenan MF, Geffner ME, Koppin CM, De Filippo RE, et al. Testicular adrenal rest tumors in boys and young adults with congenital adrenal hyperplasia. J. Urol. (2017) 197:931-6. doi: 10.1016/j.juro. 2016.09.072

16. Kang MJ, Kim JH, Lee SH, Lee YA, Shin CH, Yang SW. The prevalence of testicular adrenal rest tumors and associated factors in post pubertal patients with congenital adrenal hyperplasia caused by 21-hydroxylase deficiency. Endocr. J. (2011) 58:501-8. doi: 10.1507/endocrj.K11E-034

17. Wang Z, Yang S, Shi H, Du H, Xue L, Wang L, et al. Histopathological and immunophenotypic features of testicular tumour of the adrenogenital syndrome. Histopathology. (2011) 58:1013-8. doi: 10.1111/j.1365-2559.2011.03861.x

18. Ahmad IC, Yilmaz TF, Kocakoç E. Doppler ultrasonography and magnetic resonance imaging findings of testicular adrenal rest tissue in a patient with $11 \beta$ hydroxylase deficiency. Case Rep Med Ultrason. (2014) 16:383-5.

19. Puar T, Engels M, van Herwaarden AE, Sweep FC, Hulsbergen-van de Kaa C, Kamphuis-van Ulzen K, et al. Bilateral testicular tumors resulting in recurrent Cushing disease after bilateral adrenalectomy. J Clin Endocrinol Metab. (2017) 102:339-44. doi: 10.1210/jc.2016-2702

20. Tajima T. Health problems of adolescent and adult patients with 21-hydroxylase deficiency. Clin Pediatr Endocrinol. (2018) 27:203-13. doi: $10.1297 /$ cpe. 27.203

21. Sarafoglou K, Forlenza GP, Yaw Addo O, Kyllo J, Lteif A, Hindmarsh PC, et al. Obesity in children with congenital adrenal hyperplasia in the Minnesota cohort: importance of adjusting body mass index for height-age. Clin. Endocrinol. (2017) 86:708-16. doi: 10.1111/cen.13313
22. Clore JN, Thurby-Hay L. Glucocorticoid-induced hyperglycemia. Endocr Pract. (2009) 15:469-74. doi: 10.4158/EP08331.RAR

23. Reisch N, Flade L, Scherr M, Rottenkolber M, Pedrosa GF, Bidlingmaier $\mathrm{M}$, et al. High prevalence of reduced fecundity in men with congenital adrenal hyperplasia. J Clin Endocrinol Metab. (2009) 94:1665-70. doi: 10.1210/jc.2008-1414

24. Murphy H, George C, de Kretser D, Judd S. Successful treatment with ICSI of infertility caused by azoospermia associated with adrenal rest in the testes: case report. Hum. Reprod. (2001) 16:263-7. doi: 10.1093/humrep/ 16.2.263

25. Mouritsen A, Juul A, Jørgensen N. Improvement of semen quality in an infertile man with 21-hydroxylase deficiency, suppressed serum gonadotropins and testicular adrenal rest. Int. J. Androl. (2010) 33:518-20. doi: 10.1111/j.1365-2605.2009.00958.x

26. Chaudhari M, Johnson EK, DaJusta D, Nahata L. Testicular adrenal rest tumor screening and fertility counseling among males with congenital adrenal hyperplasia. J Pediatr Urol. (2018) 14:155.e1-e6. doi: 10.1016/j.jpurol.2017.11.011

27. White PC. Update on diagnosis and management of congenital adrenal hyperplasia due to 21-hydroxylase deficiency. Curr Opin Endocrinol Diabetes Obes. (2018) 25:178-84. doi: 10.1097/MED.00000000000 00402

28. Knudsen JL, Savage A, Mobb GE. The testicular "tumor" of adrenogenital syndrome: a persistent diagnostic pitfall. Histopathology. (1991) 19:468-70. doi: 10.1111/j.1365-2559.1991.tb00239.x

Conflict of Interest Statement: The authors declare that the research was conducted in the absence of any commercial or financial relationships that could be construed as a potential conflict of interest.

Copyright (C) 2019 Mazzilli, Stigliano, Delfino, Olana, Zamponi, Iorio, Defeudis, Cimadomo, Toscano and Mazzilli. This is an open-access article distributed under the terms of the Creative Commons Attribution License (CC BY). The use, distribution or reproduction in other forums is permitted, provided the original author(s) and the copyright owner(s) are credited and that the original publication in this journal is cited, in accordance with accepted academic practice. No use, distribution or reproduction is permitted which does not comply with these terms. 